\title{
PEMBUATAN CREAM DETERGENT UNTUK MENINGKATKAN KETRAMPILAN IBU-IBU PKK
}

\author{
Heny Kusumayanti ${ }^{1)}$, Budiyono ${ }^{2,3)}$, Ida Hayu Dwimawanti ${ }^{4,3)}$, Reny Yesiana ${ }^{5)}$, Agus Purwanto ${ }^{6,3)}$, \\ Arkhan Subari ${ }^{1)}$ \\ ${ }^{1)}$ Departemen Teknologi Dan Industri Sekolah Vokasi UNDIP \\ ${ }^{2)}$ Departemen Teknik Kimia Fakultas Teknik UNDIP \\ ${ }^{3)}$ Sekolah Vokasi UNDIP \\ ${ }^{4)}$ Departemen Administrasi Publik FISIP UNDIP \\ ${ }^{5)}$ Departemen Sipil dan Perencanaan Sekolah Vokasi UNDIP \\ ${ }^{6}$ Fakultas Ekonomika dan Bisnis UNDIP
}

\begin{abstract}
Heny Kusumayanti, Budiyono, Ida Hayu Dwimawanti, Reny Yesiana, Agus Purwanto, Arkhan Subari, in this paper explain that cream detergent is often used in everyday life, serves to wash and clean the dirt (fat). In order to commemorate the day of kartini in 2018, held a training on making cream detergent in Kp. Krapyak RT 07 RW 11 Bintoro Demak. The pH cream detergent generated from this training is 11 , this is in accordance with SNI 0062: 2016, where the pH max cream detergent is 11. The purpose of this devotion provides the transfer of science and technology appropriately to the mother of PKK and also to provide skills and entrepreneurship to PKK mothers.
\end{abstract}

Keywords: Cream detergent, PKK ladies, training

\section{PENDAHULUAN}

Semangat Kartini harus kita tiru dan kita teladani sebagai perempuan yang terampil. Seiring perkembangan waktu, ketrampilan sangat diperlukan bagi setiap orang, tidak terkecuali bagi ibu-ibu baik yang sudah memiliki pekerjaan maupun ysng sebagai ibu rumah tangga. Peringatan hari kartini 2018 ini di adakan pelatihan pembuatan cream detergent di Kp. Krapyak RT 07 RW 11 Bintoro Demak.

Sabun adalah surfaktan atau campuran surfaktan yang dilarutkan dengan air yang digunakan sehari- hari baik dalam jumlah kecil maupun besar, untuk mencuci dan membersihkan kotoran (lemak). Sabun memiliki sifat ampifilik yang pada bagian kepalanya memiliki gugus hidrofilik (polar), sedangkan pada bagian ekornya mempunyai gugus hidrofobik (non polar). Maka dari itu, gugus hidrofobik akan mengikat lemak atau kotoran dan dilarutkan dalam air oleh gugus hidrofilik (Sukeksi, 2017; Haro, 2017; Sumanto, 2016). Sabun krim atau cream detergent merupakan produk yang praktis dan ekonomis. Bahan-bahan yang digunakan dalam pembuatannya juga mudah didapat di toko-toko kimia (Sumanto, 2016).

Tujuan dilaksanakannya pengabdian kepada masyarakat ini adalah untuk transfer ilmu dan teknologi tepat guna kepada ibu-ibu PKK selain itu juga memberi ketrampilan dan berwirausaha kepada ibu-ibu PKK.

Adapun manfaat kegiatan pengabdian ini adalah ibu-ibu PKK mengetahui tentang cara kerja dan aplikasi pembuatan cream detergent sehingga bisa mempunyai manfaat lebih bagi ibu-ibu PKK, dimana cream detergent tersebut selain di pakai untuk keperluan sendiri juga bisa di pasarkan.

\section{BAHAN DAN METODE}

Bahan penelitian ini dibeli dari PT. Multi

Kimia Raya Nusantara, Semarang.

Cara Pembuatan Cream Detegent

- $\quad$ Siapkan ember berisi :

$\begin{array}{lll}\circ & \text { ABS } & 450 \mathrm{cc} \\ & \text { CMC } & 50 \mathrm{gr} \\ \circ & \text { Air } & 1000 \mathrm{cc} \\ \circ & \text { CA Crystal } & 25 \mathrm{gr} \\ \circ & \text { Air } & 1000 \mathrm{cc} \\ \circ & \text { Caustic Soda } & 25 \mathrm{gr} \\ \circ & \text { Soda Ash } & 50 \mathrm{gr} \\ \circ & \text { STTP } & 25 \mathrm{gr} \\ \circ & \text { Water Glass } & 100 \mathrm{gr} \\ \circ & \text { Parfum } & 10 \mathrm{cc} \\ \circ & \text { Zat warna/pewarna secukupnya } \\ \circ & \text { Pemutih OBA secukupnya }\end{array}$

- Ember B dan C di campur menjadi satu

- Campuran B dan C dituangkan sedikit demi sedikit ke dalam ember A

- Aduk hingga kental

- Masukkan isi ember D ke ember A, di aduk sampai rata/homogen

- Cream detergent dimasukkan ke dalam kemasan

\section{HASIL DAN PEMBAHASAN}

Cream detergent yang dihasilkan dari pelatihan berwarna putih, bau harum, $\mathrm{pH}$ 11. Sesuai dengan SNI 0062:2016, pH maks cream detergent adalah 11. Selain digunakan untuk keperluan sehari- 
hari, cream detergent juga bisa dipasarkan sehingga bisa menambah pendapatan.

Foto-foto hasil kegiatan ini ditunjukankan pada gambar 1,2,3,4 dan 5 .

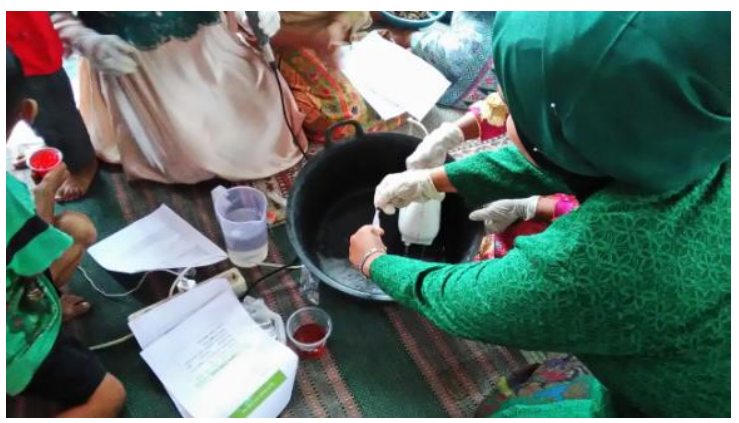

Gambar 1. Proses pembuatan detergent 1

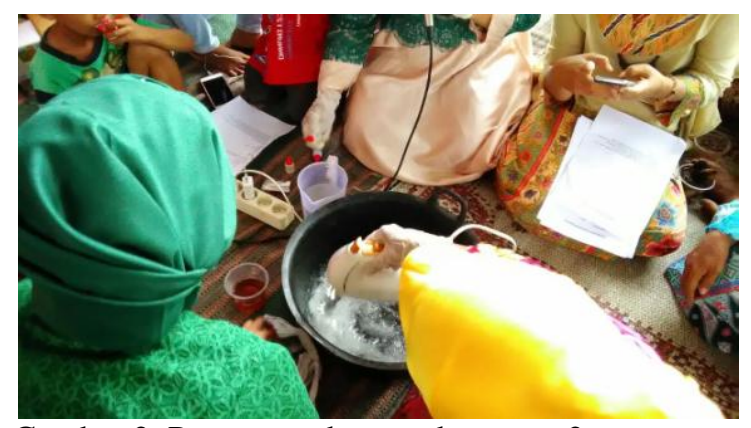

Gambar 2. Proses pembuatan detergent 2

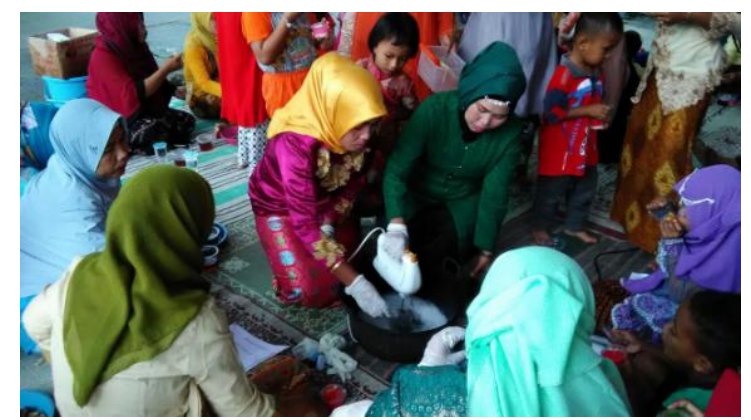

Gambar 3. Proses pembuatan detergent 3

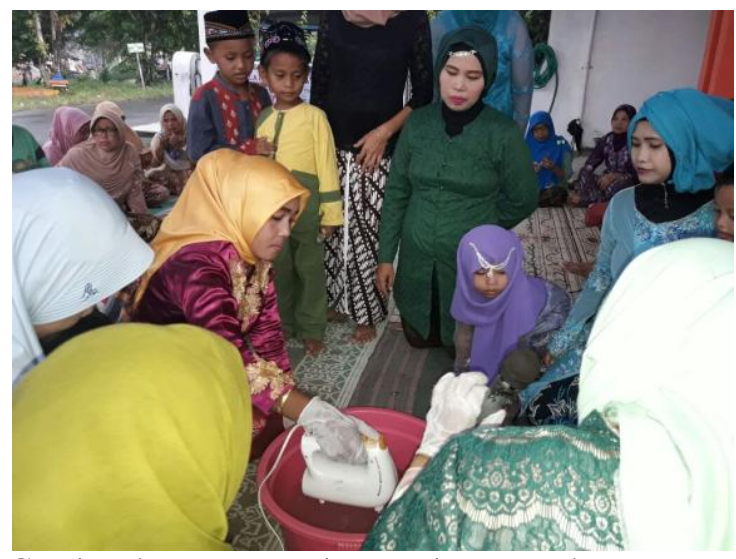

Gambar 4. Proses pembuatan detergent 4

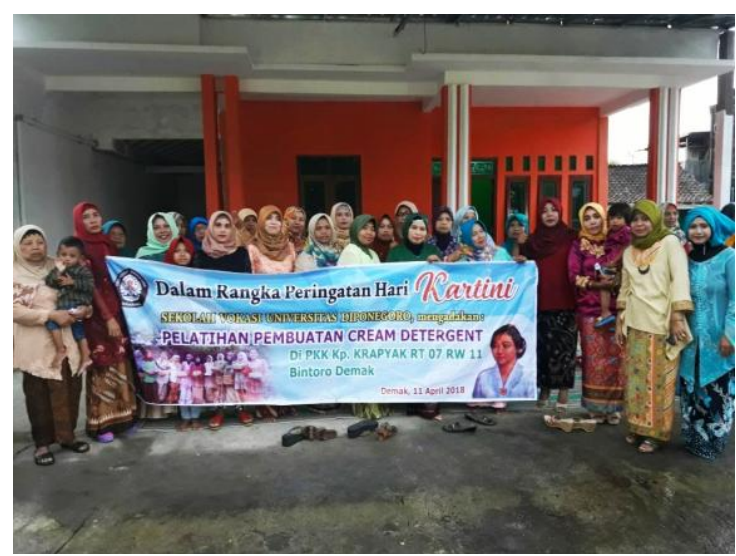

Gambar 5. Pihak-pihak terkait

\section{KESIMPULAN}

Pelatihan pembuatan cream detergent bermanfaat bagi ibu-ibu PKK, dimana cream detergent ini selain digunakan sendiri untuk kehidupan sehari-hari juga dapat pasarkan.

\section{DAFTAR PUSTAKA}

1. Haro A., Waspodo A AWS., Handaru A W. 2017. Peningkatan Ketrampilan Bagi Ibu Rumah Tangga dalam Rangka Penghematan Melalui Pembuatan Sabun Cair Sederhana. Jurnal Pemberdayaan Masyarakat Madani (JPMM), Vol.1, No. 2.

2. Sukeksi L., Sidabutar A J., Sitorus. 2017. Pembuatan Sabun dengan Menggunakan Kulit Buah Kapuk (Ceiba petandra) Sebagai Sumber Alkali. Jurnal Teknik Kimia USU, Vol. 6, No. 3.

3. Sumanto, Adriantantri E., Utomo A., Widodo B. 2016. Pembuatan Sabun Cair di Tlogomas Malang. Seminar Nasional Inovasi dan Aplikasi Teknologi di Industri (SENIATI). 